\title{
Looking at the Future of Volunteer Tourism: Commodification, Altruism and Accreditation
}

This book has proposed that volunteer tourism as a form of alternative tourism can create a tourism experience that can exist apart from a strictly profit oriented mass tourism model (MacCannell, 1976, 1992; Rojek, 1993; Urry, 2002). In doing so, it has provided a model of tourist behaviour that gives us a different perspective to the tourist experience. It also suggests this experience is more heavily influenced by motivations such as altruism than is the case with mainstream tourism, and as a result, has great potential for social change. Given these unique and valuable components of volunteer tourism, the need for accreditation and oversight is vital, but its operationalization is complex. The following is a discussion of each of these three major issues facing volunteer tourism in the not-so-near future.

\section{Commodification}

In this dominant 'market' paradigm the good life is obtained by the buying of commodities, the environment is fragmented; its holistic properties are ignored; and the costs of environmental disruption are externalised.

(Gudynas, cited in Encel \& Encel, 1991: 140)

In the last decade, Western economists, politicians and business representatives have advocated 'letting markets set the agenda'. In the case of volunteer tourism, this translates as tourists selecting their preferred option from a growing range of possibilities. If developed countries within the context of a market economy are responsible for determining the range of options available within volunteer tourism, then the agenda becomes an expression of their desire and motives, which we would argue is problematic. Just as the commodification of tourism introduces some doubt as to the ability of alternative tourism to continue in a sustainable manner, so does the commodification of volunteer 
tourism. Chapter 8 argued that providing local communities with more control over the process and allowing them to engage with the volunteer tourist in a more equal way can reduce the chance of the volunteer tourist seeing them as 'other'. We suggest here that to support this process there is a need to locate the area of volunteer tourism in a unique space that is both inside and outside of the mainstream tourism industry.

The paper 'Building a decommodified research paradigm in tourism: the contribution of NGOs' (Wearing et al., 2005) argued that Western, neoliberal, free market paradigms, coupled with Anglo-centric academics (Wearing \& Wearing, 2006; Dann \& Parrinello, 2009), continue to dominate the tourism research agenda. Wearing asserts that alternative research paradigms are needed to enrich the field and to provide new ways of seeing, researching and doing tourism. The focus of Wearing's research has been on decommodified research paradigms (Wearing \& Wearing, 1996, 1999; Wearing \& McDonald, 2002; Wearing, 2004; Wearing et al., 2005, 2010b), based upon feminist theory, ecocentrism, community development and post-structuralism. However, this should not preclude other ways of researching. A decommodified approach to tourism research opens the way for the exploration of volunteer tourism's potential to provide the means for community-defined and communitydriven development and conservation and is an issue that needs critically to inform the development of volunteer tourism. Table 9.1 sets out some of the ways that might offer alternative views, with some reasons for this approach discussed in the remainder of this chapter.

Table 9.1. Commodified mass tourism vs decommodified alternative paradigm views. Adapted from Maguire (1987: 12).

\begin{tabular}{|c|c|}
\hline Mass tourism & Alternative tourism \\
\hline $\begin{array}{l}\text { 1. Management of 'evolutionary' change } \\
\text { (survival of the fittest) within a Western } \\
\text { neoliberal rationalist approach based on } \\
\text { free market economic principles. }\end{array}$ & $\begin{array}{l}\text { 1. Radical change moving towards coopera- } \\
\text { tives and community-based approaches } \\
\text { outside of the existing tourism industry. }\end{array}$ \\
\hline $\begin{array}{l}\text { 2. Maintaining social order, existing tourism } \\
\text { systems unquestioned. }\end{array}$ & $\begin{array}{l}\text { 2. Transforming social systems, analysing } \\
\text { structural conflicts and contradictions and } \\
\text { including nature in the equation. }\end{array}$ \\
\hline $\begin{array}{l}\text { 3. Greater efficiency of current tourism } \\
\text { systems hence increased profitability. }\end{array}$ & $\begin{array}{l}\text { 3. Creating more just and equitable systems } \\
\text { that can step beyond the tourism system. }\end{array}$ \\
\hline $\begin{array}{l}\text { 4. Appearance of harmony, integration and } \\
\text { cohesion of social groups involved in the } \\
\text { tourism process. }\end{array}$ & $\begin{array}{l}\text { 4. Contradictions between social ideals and } \\
\text { reality, attempts to demonstrate this and } \\
\text { alleviate it. }\end{array}$ \\
\hline $\begin{array}{l}\text { 5. Focus on ways to maintain cohesion and } \\
\text { consensus. }\end{array}$ & $\begin{array}{l}\text { 5. Ways to dismantle or change systems of } \\
\text { domination. }\end{array}$ \\
\hline 6. Solidarity. & 6. Emancipation and liberation. \\
\hline $\begin{array}{l}\text { 7. Identifying and meeting individual needs } \\
\text { within existing social system. }\end{array}$ & $\begin{array}{l}\text { 7. Current tourism systems incapable of } \\
\text { equitably meeting basic human needs. }\end{array}$ \\
\hline $\begin{array}{l}\text { 8. Focused on actuality: discovering and } \\
\text { understanding what is. }\end{array}$ & $\begin{array}{l}\text { 8. Focused on potentiality: providing a vision } \\
\text { of what could be. }\end{array}$ \\
\hline
\end{tabular}


We would argue that a decommodified structure in tourism suggests tourist operators step away from a solely profit-orientated business plan to include a more holistic approach. In a liberal market regime, public regulation and ethical compliance is the general rule for industry. Thus volunteer tourism operators oscillate between the high-minded decommodified principles of altruistic values and sustainability, and the harsh economic reality of a privatized, competitive and, hence, highly commodified industry. It is suggested that it is necessary for some operators to attempt to move toward decommodification, despite the rule of market forces in public discourse and policy making regarding the mass tourism industry.

The aim and purpose of the following discussion is to suggest an alternative framework for volunteer tourism, particularly in terms of the relationship between volunteer tourism organizations and local communities. Volunteer tourism can only operate effectively if it is developed and interlinked with community development strategies designed to demonstrate community empowerment across a variety of sectors (McNeely \& Thorsell, 1989). These different sectors include government at a variety of levels, private enterprise, local community organizations, non-governmental organizations (NGOs) and international institutions. If each of these sectors has an understanding of where volunteer tourism fits within the broader framework of tourism and community development, and if volunteer tourism operators appreciate the importance of community inclusion in their decision making, there is a better chance of it resulting in effective, community-centred, decommodified volunteer tourism programmes. For example, volunteer tour operators need to be familiar with the appropriate behaviour, dress and even technology for each project site. In addition, by creating appreciation for the community's culture, volunteers are more likely to integrate into the community, potentially providing a more satisfying experience for all involved.

In addition to the importance of integration between volunteer tourism operators and the community, the relationship between volunteer tourism and mass tourism must also be addressed. While much of the discussion surrounding volunteer tourism centres around its potential to be engulfed by commodified mass tourism, there is great potential for volunteer tourism to impact mass tourism. Volunteer tourism is a growth area (Butcher \& Smith, 2010) and has the potential to act as a change agent in the tourism industry. The larger global political agenda (which has traditionally influenced the tourism industry overall), has moved from an environmentally centred discourse whereby the ecology of a destination is at the forefront (Kutay, 1990), toward a more community-centric, people-focused agenda. The environment is still of vital importance, but more from the standpoint of the sustainable quality of life of the human beings who reside in said environment. With this expansion in volunteer tourism, an opportunity has presented itself whereby tourist infrastructure can be planned for and approached in a way that includes: integrated planning and regulation; supply-led marketing by the tourism industry; the establishment of carrying capacities (environmental and cultural) and strict monitoring of these; and the environmentally sensitive behaviour 
and operations of tourists and operators as it relates to local, sustainable, quality of life.

In order for a community-centred approach to volunteer tourism projects to be successful, a wide range of institutions and organizations must be engaged in the channels of distribution between the host community and the potential volunteer tourist, often beyond traditional market-driven models. All play an important role in providing quality volunteer tourism experiences for both host and guest. The types of organization vary considerably and provide a wide range of services, including: international support and sponsorship for the implementation of research projects and community development that may not otherwise be available; accumulated knowledge and experience; and a large number of recruits through volunteer tourism with free time and money to spend on sustainable development projects. As part of their role as organizations which capture, recruit and prepare potential volunteer tourists, they need access to relevant educational information before, during and after their experience. This will ensure maximization of the volunteer tourism at all phases and for all involved. These non-market-driven functions often find volunteer tourism operating outside the traditional neoliberal framework.

In spite of a call for efforts to approach volunteer tourism in a way that preserves its roots outside the neoliberal market, it is clear that volunteer tourism includes a mass tourism model of packaging and segmentation as part of its bailiwick (Ellis, 2003). The literature clearly shows that volunteering as a part of mass travel has been occurring for several decades. Volunteer tourism can also be seen as a recent manifestation of the global concept of society, which prescribes that with wealth comes responsibility. Scheyvens (2002b) identifies volunteer tourism as a form of 'justice tourism', as it 'involves individuals from Western countries paying to come to the Third World to assist with development or conservation work, as they desire to achieve something more meaningful than a pleasure filled, self-indulgent holiday' (p. 202). The success and popularity of both the idea and the manifestation of volunteer tourism has led to its commodification in a similar manner to its alternative predecessor, ecotourism (Wearing \& Neil, 2000). The challenge now is to work to find a way forward that can resolve the tension between the non-commodified values and ethos of volunteer tourism with the dominant Western market place ideology. Perhaps part of the answer lies in the exploration of the motivations behind volunteer tourism.

As indicated in Chapter 5, motivations for volunteer tourism are not homogenous. Brown and Lehto (2005) suggest that some participants are more 'volunteer-minded' (altruistic) and prefer to spend most of their time doing volunteer work at the destination, while others are 'vacation-minded' (self-interested) and want to focus on tourism-oriented activities while minimizing volunteer time. Conversely, Sin (2009) found that the motivations of volunteers often revolved around the desire to visit an exotic destination (adventure or escape). However, altruism does rise to the top in numerous studies as the overwhelming primary motive for many volunteer tourists. It is also one of the most controversial. As a result, it deserves special attention. 


\section{Altruism (is not a Dirty Word)}

Fortunately, not all views of the third sector interpret it in an economic way.

Rubin (1990), for example, claims that nonprofits are comprehensible through their 'altruism.' TSOs (Tourism Sending Organisations), for Rubin, are so diverse that only their altruism can be used as a common element in defining them.

(Clohesy, 2000: 239)

Have we reached a place in the study of volunteer tourism where we can say with confidence that we truly understand the motivations of the volunteer tourists? If the end result of volunteer tourism has the same impact on the community regardless of motivation, does it matter if the tourist is motivated by altruism? Are the benefits and negative impacts felt any differently? These are all difficult questions and not easily answered.

In answer to the first question, we can say with some confidence that altruism is one of the most common motives associated with volunteer tourism. However, many volunteer tourists may disguise their search for self-discovery behind their altruistic façade (even if that façade is genuine). Self-discovery during any travel experience is inevitable, and should not be seen as simply a selfcentred, egotistical endeavour. Altruism, coupled with self-discovery, is a powerful mechanism for social change (McGehee, 2012). As long as altruism is at least a part of the mix, the potential for change for the host community, the volunteer tourist and even the world is high.

Perhaps where these questions become most interesting is via the economic relationship between volunteer tourist and volunteer tourism organization. Wearing (2001: 215) describes volunteer tourists as being 'altruistically motivated consumers'. When altruism is part of the marketing mix, it becomes commodified, packaged and sold by the tourism industry for a profit, often at a higher price than projects that merely target self-discovery or adventure. Just as nature has been commodified as a part of the process of developing ecotourism, so has altruism been commodified as part of the process of developing volunteer tourism. There is little doubt that some degree of empathy plays a role in altruistic practices (Staub, 1991). Having empathetic feelings towards other humans, animals or the environment becomes the first step in developing a sense of value and care towards their sometimes detrimental situations. Over time, this sense of value can become independent of empathy and be instilled into the belief system and personal goals of the individual, consciously or unconsciously. In this manner, altruistic motives can become commodified.

This complex connection between the market and the individual can be explained in a number of ways, including personal values, moral principles and choosing to make the personal political. First, personal values and the value systems developed by individuals can be recognized as playing a key role in predicting human behaviour in various contexts, including participation in tourism activities (Madrigal, 1995). Thus they are able to be used by the marketplace to create a market mechanism that will return a profit based on one's 
personal values and value systems. Volunteer tourism is partly rooted in a tourist's desire to fulfil particular altruistic needs, thus motivating them to participate. The marketplace can encapsulate that to make a profit.

Second, the development of altruism also comes from one's moral principles. These principles are manifest as societal expectations. For example, it is expected that people should help others in need. A common example of these societal expectations can be seen in the fundraising activity of many not-forprofit organizations where campaigns are based firmly around notions of empathy and altruism.

Third, and closely related to societal expectations, is the notion of the personal as political (Srivastava, 2003). An example of this concept is found in Taylor and Whittier's (1992) examination of lesbian feminist mobilization. Women who participate and support the movement do not limit their involvement to political activism such as letter-writing campaigns and protests, but include activism in every aspect of their personal lives, including their consumption. For example, women of the movement may shop only at gayfriendly stores, subscribe to magazines that promote their political and social platform, and travel using only gay-friendly airlines, accommodations and restaurants. Altruistic volunteer tourists may also adopt this mindset, making financial choices based upon their political and personal values. Given this perspective, the answer to the latter questions asked at the beginning of this segment is yes, it does matter, and yes, the impacts can be felt differently depending on the motivation, moral principles and personal values of the volunteer tourist.

\section{The Role of Accreditation in the Future of Volunteer Tourism}

Discussion surrounding the potential, pitfalls and paradoxes of volunteer tourism, including the aforementioned subjects of commodification and motivation, has naturally led to a debate over accreditation. Volunteer tourism operators, organizers, pundits and researchers have included the idea of accreditation as one viable way to minimize the negative impacts of volunteer tourism while maximizing the positive, and in particular to monitor and control the impacts of projects on host communities. In many ways, the conversation mirrors the discussion regarding ecotourism certification in previous decades (Wearing, 2001; Tomazos \& Butler, 2009a), including many similar contentions and challenges. The nature of all forms of tourism makes voluntary compliance with a set of standards incredibly difficult, as the industry is fragmented, highly competitive and typically comprised of small, marginally profitable operators. Some of the challenges that are particularly difficult for volunteer tourism include:

- lack of reciprocity/homogenization amongst the bodies, organizations and companies engaged in volunteer tourism;

- lack of governmental appreciation and support;

- unsustainable practices in destination communities; 
- no mechanism to check the local community's assessment of volunteer impacts; and

- $\quad$ potential volunteers having incomplete information regarding what is really being offered.

In spite, or perhaps because of, these challenges, the pursuit of a viable means of accreditation is important in that it may be a way to offer a movement toward a paradigm-shifting, decommodified and truly alternative form of tourism. Accreditation offers the potential for this level of change, in that it provides:

- credibility;

- international/regional recognition;

- stakeholder involvement;

- organization;

- continuous improvement;

- $\quad$ political and financial support;

- conflict resolution;

- protection against false claims; and

- consistency.

As with any type of accreditation, there are basic steps needed at the onset of the process in order to create an accreditation system that is effective and beneficial for everyone involved. This foundation is particularly important for volunteer tourism at a time when its potential for positive global impact is great. These steps include:

- a needs assessment of the different stakeholders;

- a white paper analysing market demand for the accreditation of volunteer tourism and documenting the feasibility/need to establish an accreditation body;

- recommendations for accreditation criteria;

- a proposal for establishing and maintaining an accreditation volunteer tourism organization that could be taken to an international organization such as the WTO for further funding;

- a complete organizational blueprint and implementation plan; and

- organization of preliminary meetings with key players.

Once the groundwork has been established, the next step involves governance. In order to operationalize any accreditation process, some form of governance is a basic requirement. The responsibilities of an accreditation body would most likely be to:

- help establish a generic standard for volunteer tourism;

- $\quad$ support the definition of local standards for each country or region;

- establish accreditation criteria for tourism certifiers;

- $\quad$ accredit certifiers;

- guarantee stakeholders' participation;

- $\quad$ promote accreditation system and standards; and

- $\quad$ perform random audits of certifiers and companies. 
Governance is a vital component, but a word of caution is necessary at this point. While the notion of having both a global volunteer tourism body as well as local-level governance is supported by many, Font \& Skinner (2003) also remind us that the large number of tourism certification programmes in mainstream tourism has led to market confusion and high start-up costs for small operators and organizations. Because of this, thoughtful consideration of synergies with existing organizations is very important. For example, are there existing governing bodies that may be able to build upon their experience and expertise without creating a new infrastructure? The Ecotourism Society (TIES), for example, may be one such existing body. This alliance, coupled with a means by which certification can be locally customizable, would maximize its impact.

Volunteer tourism projects as a result of this sort of standard would then be more likely to:

- have a coordinating organization;

- facilitate an industry coalition for the supervision of the project;

- contribute to cultural understanding between volunteers and locals;

- $\quad$ assure stakeholder participation and consensus building, e.g. locals involved in the management of protected areas;

- only award certification to projects that directly benefit the community;

- assure projects have a minimal impact on the socio-cultural fabric of the community;

- $\quad$ provide guidance for implementation of results; and

- explore additional accreditation, marketing and technical assistance.

\section{A Final Word: Expanding the Research Agenda for Volunteer Tourism}

\section{Toward a more inclusive understanding of volunteer tourism}

The rigid categorization of volunteer tourism in either its supply or demandsided manifestation overlooks the vague margins where a range of ambiguities are experienced by individuals who at some level may be at once tourist, local and tourism provider.

Research has provided a wealth of typological models that help classify behaviours. These taxonomies have been developed based on a broad range of increasingly sophisticated criteria associated with social roles, motivations, activity types, socio-demographics, travel experiences, lifestyles, values and personality (Lyons, 2003). Proponents of typological research argue that it provides a valuable foundation upon which action can be taken. For example, the principles of market segmentation in tourism are based on the premise that particular types of travellers can be categorized and their needs identified and met through the development of niche products. However, Franklin and Crang (2001) argue that the proliferation of increasingly fine-tuned and elaborate typologies and a general 'craze for classification' (p. 6) has emerged from viewing tourism as 'a series of discrete, enumerated occurrences of travel, arrival, 
activity, purchase, departure' (p. 13), where tourists are seen as another incarnation of 'Rational Economic Man' (p. 13). As a result, there has been an unchallenged belief underlying travel and tourism research that increasingly finer tuned and elaborate typologies will eventually form a classificatory grid in which definition and regulation can occur (Franklin \& Crang, 2001). In contrast, Cohen (1979) has argued that it is precisely the fuzziness of tourism categories and the blurred margins it creates that enables conceptual relationships and advancements to be made with other forms of social and cultural activities. Three examples of this 'fuzziness' provide some critical understanding of this intersection, which may be overlooked if a narrower and more rigid view is adopted. Service learning, cultural exchange programmes and fundraising adventure tourism each challenge conventional views of volunteer tourism.

The promise of skills development and improved employability underpins a number of international volunteering experiences that are not branded as volunteer tourism but are packaged and marketed, primarily by universities in developed countries such as Australia and the USA, as service learning. Jacoby and Associates (1996, 2003) explain that, unlike traditional models of work experience, service learning is unique because it is based upon reciprocity and reflection. Reciprocity refers to what is traditionally the central focus of work experiences where volunteer learners provide their labour, and in return, gain skills and knowledge from the experience. The reflection component involves a mirroring process where students examine how an experience relates to how they see themselves and how they would like to be seen (Brown \& McCartney, 1999).

While the value of service learning has been analysed and documented (Myers-Lipton, 1996; Ellis, 1997; O’Grady, 2000; Clark \& Young, 2005), warnings have been sounded about the impact of volunteer tourism upon hostvisitor relationships and understandings. As Grusky (2000: 858) suggests:
International service-learning programs burst with potential and stumble with the weight of contradictions left unattended. Without thoughtful preparation, orientation, program developments and the encouragement of study, as well as critical analysis and reflection, the programs can easily become small theaters that recreate historic cultural misunderstandings and simplistic stereotypes and replay, on a more intimate scale, the huge disparities in income and opportunity that characterize North-South relations today.

Despite the proliferation of and advocacy for service learning in higher education, the activity has received scant serious research attention. Duguid et al. (2006) suggest that this is due to unpaid work in general, such as volunteering, not being considered real work and thus is regarded by policy makers and the general public as more trivial than paid work. In addition, informal learning is at the margins of education and thus too difficult to research. Nearly 10 years after Ellis' (1997) critique, Butin (2006: 1) acknowledges that there is still a lack of overall research into service learning despite its growth:

... service learning has been embraced by the academy to a much greater extent than it has been scrutinized. To acknowledge this fact, though, risks exposing an underside of service learning that most advocates would rather avoid: namely, that service learning, as any other educational reform model, 
has its own blind spots, its own unacknowledged and unexamined assumptions, and its own impositional narratives.

The rising trend in education toward requiring graduates to undertake voluntary service abroad raises important questions about efficacy and ethics. As Stebbins states (2009), 'A key element in this leisure conception of volunteering is the felt absence of coercion, moral or otherwise, to undertake a particular activity' (p. 155). It is unknown whether the reduction or removal of choice from these volunteer tourists impacts the quality of their voluntary work, the degree to which it creates cultural empathy and understanding, and whether it creates more problems for host communities than it solves.

The second example, cultural exchange programmes, have long been associated with promoting tolerance, goodwill and understanding of cultural differences (White, 2002), and have been identified by politicians as a cure-all to a range of deeply ingrained regional conflicts (Netanyahu, 1998). Proponents of programmes designed to facilitate cultural exchange emphasize their importance in terms of broad macro-level relationships between countries and cultures that help rid nations of 'neo-coloniality' (Altbach \& Lewis, 1998: 54). However, some critics argue that much of the rhetoric about the value of exchange programmes masks the fact that cultural exchange reinforces capitalism and the values of globalization (Iriye, 1997; Davies, 2005). These ideological debates about the purpose and role of cultural exchange suggest that these programmes are indeed contexts rife with ambiguities. These debates were highlighted in the Cuban ambassador case study in Chapter 6.

Although macro-claims and concerns about cultural exchange programmes are worthy of consideration, it is the direct micro-interactions between participants and host communities that are central to understanding cultural exchange programmes. It is at this micro-level that an overlap between volunteer tourism and cultural exchange becomes more evident. Wearing (2001) has argued that it is the minutia of direct interaction between the volunteer tourist and the host community that promotes long-lasting, socially and environmentally positive impacts. This interactive exchange described by Wearing suggests that volunteer tourism may well be viewed as a subset of cultural exchange. However, it is also at this micro-level of interaction where ambiguities associated with participants' roles in cultural exchange programmes become reality.

Over the past half century, there has been a shift away from primarily education-based cultural exchange programmes that proliferated in the 1960s and 70s such as teacher and student exchanges, toward more eclectic programmes that incorporate an ever-growing range of occupations and recreational pursuits (Murphy, 1995; Lyons et al., 2012). Accompanying these newer programmes is a complex relationship between the participant, host organizations, sponsoring agencies, and host country legal and political entities. Participants in these contemporary exchange programmes negotiate their way through an array of ambiguous and sometimes conflicting roles.

The development of the third ambiguous form of volunteer tourism known as fundraising adventure tourism is a recent innovation on the part of NGOs. This phenomenon raises important questions about whether volunteering and 
touring components of volunteer tourism need to be in the same temporal and geographical space in order to be classified as such. NGOs have had to face the very real issues of economic sustainability that is central to the viability of the community-based projects they provide. In the early 1980s, increasing pressure upon NGOs and other non-profit organizations led many executive directors to explore creative alternatives for fund-raising and financial support. While traditional forms of revenue had previously come from grants and philanthropists, the tightening of belts associated with the recession and the economic rationalism of multi-corporates led to diminishing funds (Dichter, 1999).

Subsequently, increasingly sophisticated approaches to funding NGO projects emerged that moved beyond traditional funding drives such as telethons or door knock appeals. The notion of value-adding crept into NGO fundraising strategies in the early 1970s, when community events such as walkathons, fun runs and other competitive and non-competitive events became important fundraising products for these organizations (Dichter, 1999). This more modern form of fundraising is a departure from these leisure activities, blending the voluntary act of fundraising with the more traditional hedonic pleasures of a packaged adventure tour, positioning them as an ambiguous form of volunteer tourism. This transformation was also well received by Generations X and Y as a way to do good but have a good time doing it. This becomes even more relevant if we agree with data from such as Pearce and Coghlan (2008), who found that volunteer tourism is most commonly undertaken by Generation $\mathrm{Y}^{1}$ and to a lesser extent Generation X. ${ }^{2}$ Generation $\mathrm{Y}$ is seen to have a whole new set of attitudes, values and beliefs compared with previous generations (Hatfield, 2002). In Hatfield's commentary (2002: 73), Eric Chester commented that Generation $Y$ 'are better educated, more creative and far more techno-savvy that those who have come before them'. Participation in volunteer tourism is attributed to their interests and knowledge in sustainability of the environment as well as global issues such as poverty and hunger (Pearce \& Coghlan, 2008). It was found that Generation $Y$ is considered to have a prolonged adolescence because of the continual support from their parents into young adulthood, thus giving this generation an opportunity to pursue causes and explore experiences that volunteer tourism may offer (Pearce \& Coghlan, 2008). Finally, Generation Y participates in activities that aid in the process that help define 'who they are, what is most important to them and what they value the most' (Noble et al., 2009: 620). This form of volunteer tourism challenges the necessity for the simultaneity of volunteering and touring in volunteer tourism. It raises questions about the act of volunteering and whether it can be experienced more remotely and independently in space and time from the act of touring.

The three examples of service learning, cultural exchange and adventure fundraising tourism create a challenge to current views and approaches to volunteer tourism. They illustrate how a narrow treatment of volunteer tourism does not fully capture the realities of the many who are exposed to a multitude of opportunities and challenges that may at once render them classifiable as volunteer tourists, students, package tourists, exchange participants, employees, fundraisers or a number of other designations. Rather than trying to 
pigeonhole characteristics, interests or behaviours, it is valuable to focus upon how volunteering and tourist behaviours intersect and manifest in a variety of ways. Below are several suggestions for ways to reconsider and expand the volunteer tourism research paradigm.

\section{The future of volunteer tourism research}

The bulk of research on volunteer tourism conceptualizes it as a form of 'alternative tourism', which views the tourist destination as an interactive space where tourists become creative, interacting volunteers who engage in behaviours that are mutually beneficial to host communities, the cultural and social environment of those communities, and the individual volunteer tourist who takes home an experience that impacts on the self in some way (Wearing, 2001; McGehee, 2002; McGehee \& Norman, 2002; Lyons, 2003). We question the continuing viability of this conceptualization in light of the growing commercial interest in the development of volunteer tourism products. This includes work that sits at the margins of both volunteering and tourism (Lyons, 2003; Holmes \& Smith, 2009) and that moves beyond the craze for classification in tourism research (Franklin \& Crang, 2001). This work reveals that such an ideology can be usurped and diverted by hegemonic forces of late capitalism. A central question that emerges then is whether a philosophy and practice of volunteer tourism that extends beyond market priorities can be sustained in the global tourism marketplace.

The current state of volunteer tourism research has emerged somewhat ad hoc and lacks a coordinated framework for further development. Three key directions that have thus far underpinned this research are the study of the volunteer tourist experiences, motives and behaviours; the analysis of communities who host and are impacted by volunteer tourists; and the examination of the development and supply of volunteer tourism services and products. Previous research on volunteer tourism has primarily focused upon the motives and experience of the tourists themselves through small-scale case studies that consider specific instances of volunteer tourism in action. While we recognize this work provides rich data and important insights, there is a need for broader population-level analyses that provide more data on the scope and extent of volunteer tourist behaviour, allowing a wide frame of reference to capture activities at the fuzzy boundaries of volunteering and tourism. For example, McGehee's (2012) work sets out to create a theoretical framework that rests on a foundation of both critical theory and social movement theory, coupled with specific propositions, as a way to approach the study of volunteer tourism in a systematic way that includes its interaction with larger social systems and ultimately an impact on the dominant hegemony. More work like this is needed in volunteer tourism.

The research on host communities and volunteer tourism is still relatively limited and focuses primarily upon the voices of NGOs and community leaders. We suggest that this research needs to be expanded to include the voices of under-represented stakeholders who may inadvertently be further marginalized 
by volunteers. We also argue that the long-term impacts of volunteer tourism on the host community are under-researched. Little is known about the shortand long-term social, economic and cultural effects that volunteer tourism brings. We argue that social and economic modelling is needed not only of the benefits but also the costs that volunteer tourism brings to these communities.

The existing research on the provision of volunteer tourism service and products is also limited, focusing primarily on the challenges and issues faced by NGOs who oversee volunteer tourism projects in developing countries. However, there is a dearth of research on the fast-growing supply of commercial volunteer tourism products. There are virtually no empirical data that describe the practices or impacts of commercial volunteer tourism activities outside of the anecdotal and critical/theoretical work that posits NGO-based volunteer tourism as 'all good' - and corporate and commercial interests as 'all bad' (Wearing et al., 2005). We argue that this starkly dichotomous view does not account for the increasingly blurry and overlapping relationships that are beginning to emerge in volunteer tourism between NGOs and commercial operators and suggest this is an area of research that needs to be urgently developed.

This research agenda framework has its boundaries. These boundaries are drawn widely around the relationships between developing and developed countries that occur through the social, economic and environmental aspects of tourism development, from the local to the global, in all regions around the world. Research in this area should be conceptual, theoretical and empirical, particularly where it contributes to the dissemination of new ideas, new theory or models and seeks to find ideas that represent best practice in the social development of communities through volunteer tourism. Moreover, we argue that the empirical research needs to span both qualitative case analyses and macro-quantitative data, providing a more comprehensive picture of the breadth and depth of the phenomenon of volunteer tourism globally. As such, the research agenda should attempt to be transdisciplinary and transnational. It is hoped through this broadening of the research parameters, the intersection of volunteering and tourism can be more deeply explored, more richly understood and more adeptly managed.

\section{Notes}

${ }^{1}$ Individuals born after 1980 through to 2000 (Hatfield, 2002).

2Born between 1965 and 1980, these individuals grew up during trying times, both socially and politically, and they tend to be quite independent (Hatfield, 2002). 